\title{
Design and fabrication of potters kick wheel for ceramic wares production
}

\author{
Olusola Joseph Ajayi ${ }^{1,}{ }^{*}$, Tolulope Sayo Toludare ${ }^{2}$ and Yinusa Daniel Lamidi ${ }^{1}$ \\ 1 Department of Glass and Ceramics, Federal Polytechnic, P.M.B 5351 Ado Ekiti, Nigeria. \\ 2 Department of Industrial Design, Federal University of Technology, P.M.B 704 Akure, Nigeria.
}

Global Journal of Engineering and Technology Advances, 2021, 06(01), 099-107

Publication history: Received on 12 January 2021; revised on 20 January 2021; accepted on 22 January 2021

Article DOI: https://doi.org/10.30574/gjeta.2021.6.1.0006

\begin{abstract}
An attempted to produce or fabricate a functional kick wheel have failed because some important principles guiding the fabrication of the kick wheel was neglected. Some of these are improper centered wheel head and low rotating force from the fly wheel. In this research, a design was generated in a bid to produce a functional kick wheel for pottery production using a marsonial wood for the skeletal part. The kick wheel was designed in such a way that the fly wheel and the centering can be self-controlled. Low cost of materials, reduced energy, lesser stress and conveniences during operation are all considered in the design principle. From the result of the ceramic ware produced, it was discovered that the machine can produce hollow ware with a well centered base with the advantage of self-reliant, no energy cost and less stress during usage.
\end{abstract}

Keywords: Kick wheel; Fly wheel; Centering

\section{Introduction}

The quest for constructing machine and equipment as well as self-reliant and self-sufficiency advocacy, has compelled many developing countries such as Nigeria where power "Electricity" is not guaranteed to power ceramics equipment anytime, including researchers in the universities, polytechnics and local potters to go into fabrications of some vital and/ necessary equipment to be used for productions of pottery wares in the workshop. The wheel is a simple equipment which every studio potter desire and requires as well $[1,3]$. A simple manual wheel may have just the wheel head and a flywheel, suspended on a rigid wooden or metal stand and is being operated with the hand or foot $[4,5]$. The wheel head necessarily has to be heavy to enable the machine gather enough momentum for the required speed during the operation [5]. The wheel "consist of a wheel-head, or disk, which revolves with considerable momentum and smooth control of speed and is driven by hand or foot, or by gear. The momentum is obtained from either a heavy wheel-head or from a fly wheel" [1].

However, some of the wheels have always been associated with one problem or the other. The electric wheel has not been a total solution to the potter's problem in this regard because of the epileptic power supply in our various communities. One of the goals of embarking on a manual potter's wheel is to "ensure that its adaptability shall adequately provide efficiency even in the absence of electricity, making it a dependable source for production of pottery wares" [2]. The non-availability of the potter's wheel in the potter's studio has therefore posed a big challenge to the potter and as such, demands for urgent solution. Attempts are therefore made to construct a potter's wheel using the shaft, to alleviate the potters challenge in the quest for a reliable wheel that will stand the test of time for his pottery production. The "wheel is the tool of the potter, allowing him to use his skill to quickly produce beautifully shaped pieces, so that they have the freshness and vitality of quick sketches" [3]. The wheel is an indispensable and

\footnotetext{
${ }^{*}$ Corresponding author: Ajayi OJ

Department of Glass and Ceramics, Federal Polytechnic, P.M.B 5351 Ado Ekiti, Nigeria.

Copyright (C 2021 Author(s) retain the copyright of this article. This article is published under the terms of the Creative Commons Attribution Liscense 4.0.
} 
useful tool in the ceramic studio for the production of hollowed ceramic wares, and at the same time its presence enriches the studio environment [4].

\section{Material and methods}

- flat $10 \mathrm{~mm}$ thick wood of $30 \mathrm{~cm}$ diameter

- $20 \mathrm{~mm}$ nuts

- Self-aligning 1 inch (6205 or $25 \mathrm{~mm}$ ) bearings

- $25 \mathrm{~mm}$ Shaft

- Flat joint bars

- Angle bars

- Shaft connector

- Boris

- Aluminum metal sheets

- Chain

- Metal adjuster

- $10 \mathrm{~mm}$ drain pipe

- 17 carriage Bolts 5x3/8 inch

- Vanish, paint

\subsection{Parts That Makes Up the Treadle Kick Wheel}

The treadle kick wheel comprises of several units that makes a whole machine, these parts are crucial to the functionality of the machine. These parts are made of two materials which are: wood and metal (iron). The following are the different parts

\subsubsection{The Wheel Head}

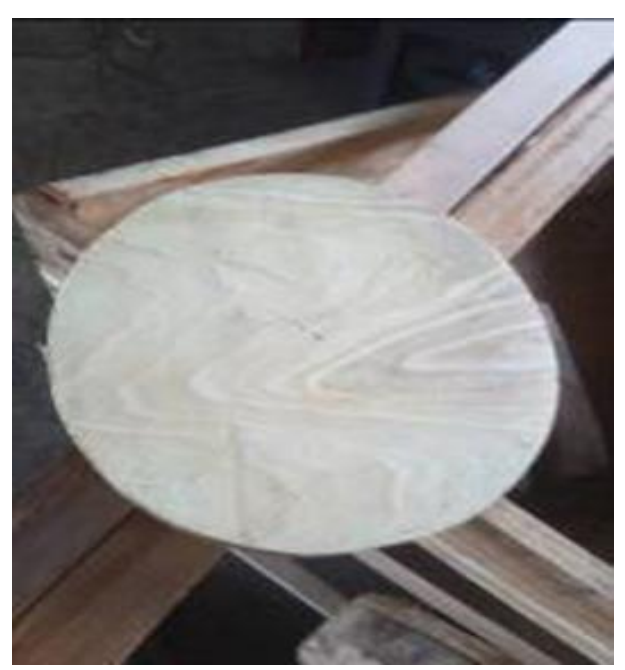

Plate 1 Wheel Head

The wheel head is fashioned out from a flat $10 \mathrm{~mm}$ thick wood and cut to a diameter of $30 \mathrm{~cm}$. To achieve a perfect circle, the aid of a compass is required to mark out the size, and is cut with a circular saw. A $20 \mathrm{~mm}$ nut is then screwed to the center of the wooden wheel head with which it would be screwed on to the $20 \mathrm{~mm}$ shaft bolt that protrudes from the top of the axel. The wheel head necessarily has to be thick and heavy enough [4]. This will aid in balancing of the wheel head and avoid a situation whereby a wheel head dances and thereby prevents usage [8]. Concentric circles are also marked on the reverse side of the plate with a sharp tool. The circles are also necessary as they aid the potter during centering of clay while throwing and also during turning and dressing of his thrown pieces $[7,9]$. This flat $30 \mathrm{~cm}$ wood now functions as the wheel head.

\subsection{Splash Tray}

The splash tray is constructed with $12 \mathrm{~mm}$ resin banded plywood. It is a square open container measuring $2 \mathrm{ft} 10^{\prime \prime} \mathrm{x} 1 \mathrm{ft}$ $4 "$ at the top with the length of the back face board measuring $306 \mathrm{~mm}$, tapering backward. It is constructed to have 
enough space around it to place a bowl of water and other working tools while throwing on the wheel. An opening of about $12 \mathrm{~cm}$ by $12 \mathrm{~cm}$ is cut at the bottom center of the tray through which the shaft of the axel will protrude to bear the wheel head. A shallow wall of about $6 \mathrm{~cm}$ is raised around the opening with the pan, to stop water or clay slurry from spilling off the tray onto the axel and the floor during throwing. The tray therefore serves as a receptacle for both water and the clay slurry during throwing. (A large, stiff and shallow plastic bowl could also be fashioned to serve this purpose). This will be mounted on the framework before the wheel head is screwed on. The inner part of the splash tray is lined with aluminum sheet to help repel water and at the same time to ease cleaning.

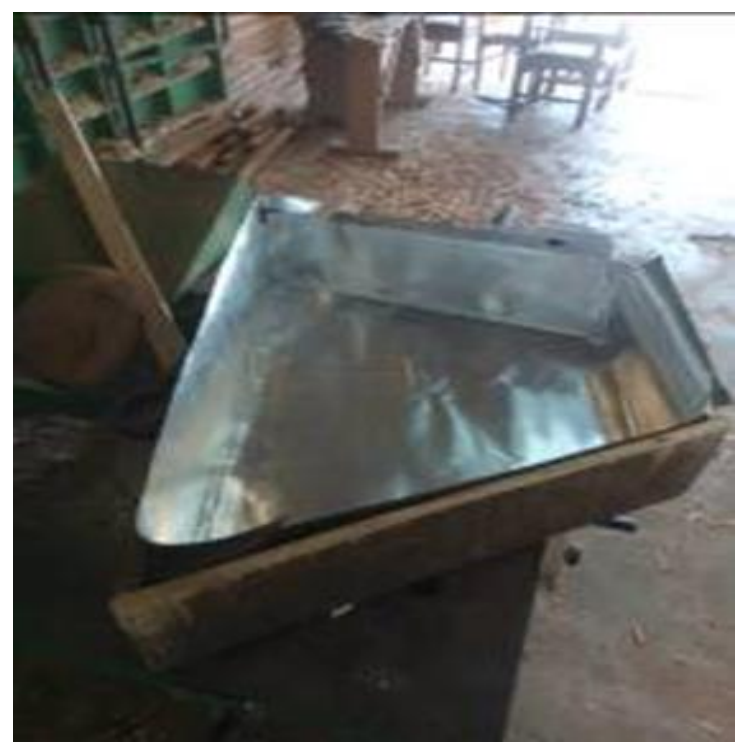

Plate 2 Splash Tray

\subsubsection{Fly wheel}

The standard flywheel is $2 \mathrm{ft} 4$ inches wide and 4 inches thick [4, 5]. It is made of planks glued and screwed at right angles to each other. The wood used for the fly wheel is known as Taminalia Efforensis, also called "black afara". The fly wheel is required to be heavy as this will help to gather easy momentum while working especially while centering, the difference between this design and existing designs is the fly wheel. Some of the existing designs lacks a fly wheel which makes it difficult to use as it causes fatigue to its user in a very short period of time. This design includes a fly wheel that will rectify that laps, heavy enough to spin the wheel head at such a great speed with very little effort from the user.
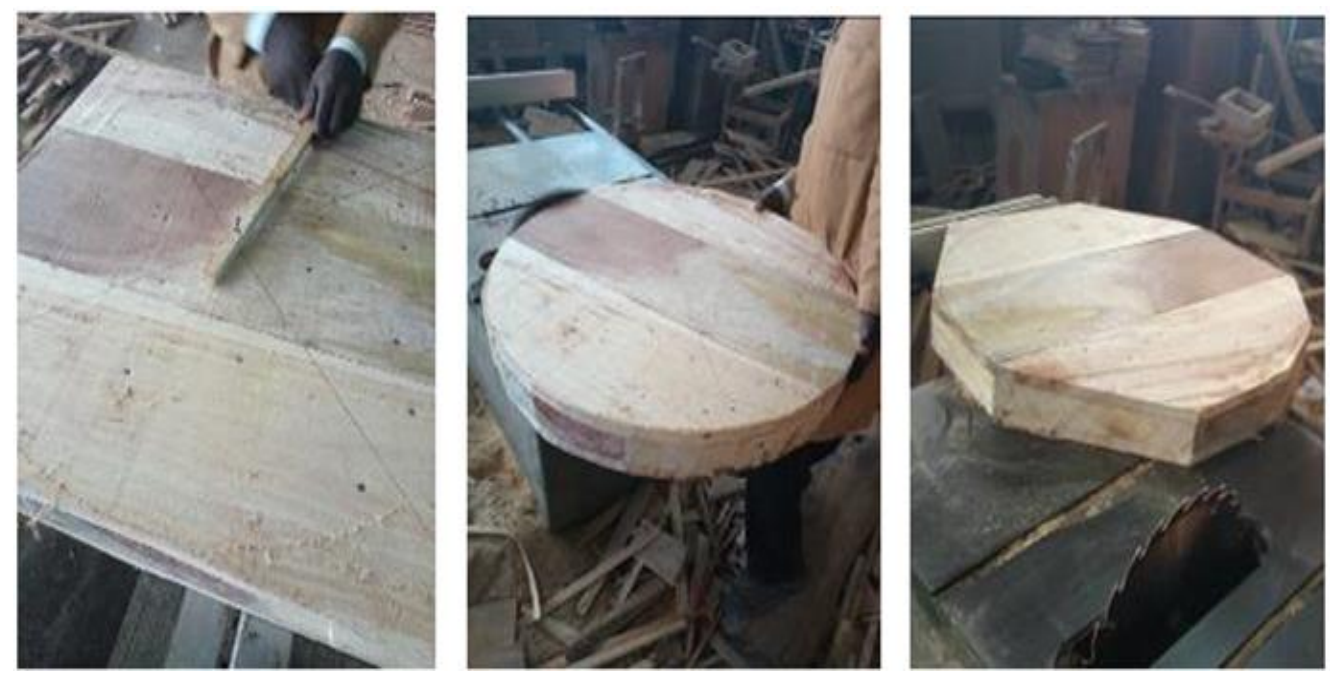

Plate 3 Fly Wheel 


\subsubsection{The Shaft}

The shaft is made of $25 \mathrm{~mm}$ round steel. The shaft joints are welded whilst the shaft is turning slowly, this makes the weld even and prevents stress from setting up in the metal. The shaft is made with section R in place which is only removed after all the welding has been completed. The shaft's crank is off-set by 3 inches, which gives a smooth fairly fast running wheel head. If this is decreased by up to $3 / 4$ inch it will run faster; if it is increased by up to 1 inch the wheel will run slower. However, the 3 inch offset suits most people. The plates are 2 inches wide. The wheel head fitting, is a number 3 morse taper. The other standard fittings are a $3 / 4$ inch [6]. Whitworth screw and $20 \mathrm{~mm}$ continental screw.

\subsubsection{Kick Bar}

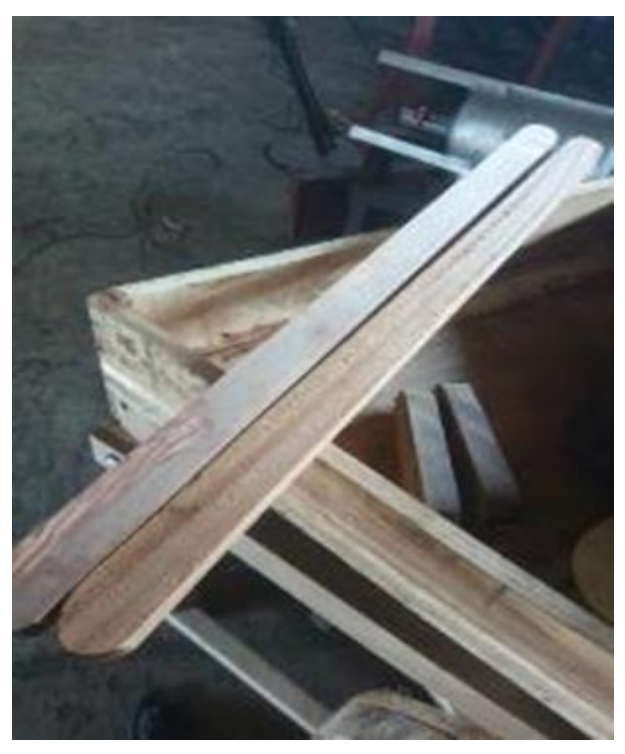

Plate 4 Kick Bar

This is made 2X60inch flat and long wood. It has two screw holes in it by which it is attached to the leg of the wheel, the first joint on the kick bar connects the bar to the adjuster on the leg of the wheel, this enables it to be adjustable depending on the height of the user, the second screw hooks a chain to the kick bar, this helps suspends the kick bar and aids easy movement. The chain is connected to the outer side of the splash tray with the aid of a hook, the chain also allows the kick bar to be adjusted depending on the height of the potter.

\section{Fabrication transition process}

\subsection{Research Findings}

In the research findings, it was observed that most of the throwing wheels that are available in most cottage potter studio are manual and electrical. The manual is constructed, which is a limiting factor to their life span. The ones made from just metal corrodes in relation to time and constant contact of water and then makes so much noise when it is not well lubricated. The electrical wheels are limited to instability of power supply, it was decided in solution to the two challenges that wooden frame would better suit the machine. This machine does not require electricity to power it, another advantage is the noise is drastically reduced from the shaft by incorporating a ball bearing to the shaft and kick bar connector. It is driven by kick force that sets the fly wheel on continuous rotation motion [10]. The weight of the fly wheel determines how fast and how long the speed of the wheel will last [5]. The fly wheel is connected by the shaft to the wheel head, where a cone protects the protrusion of the shaft underneath the wheel head. 


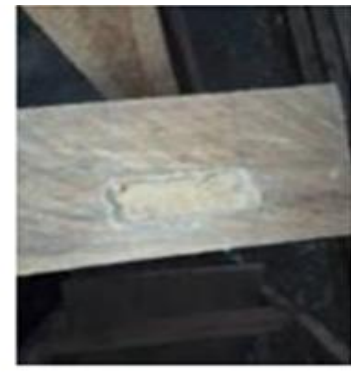

Plate 5: drilling the mortise and tenon joint

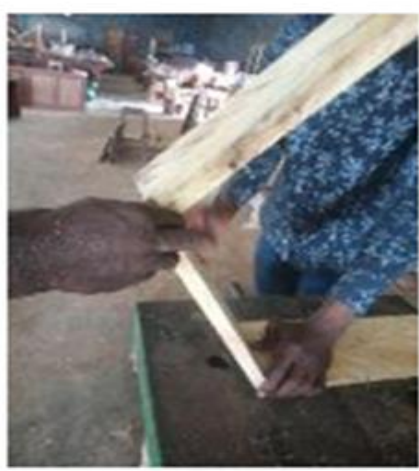

Plate 8: Splash Tray

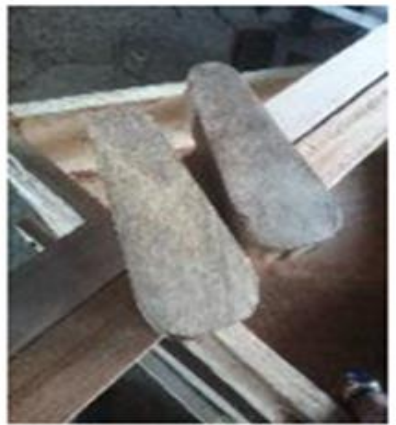

Plate 11: Shaft and kick bar Connector

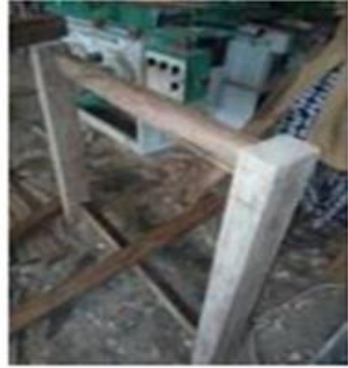

Plate 6: coupling the frame

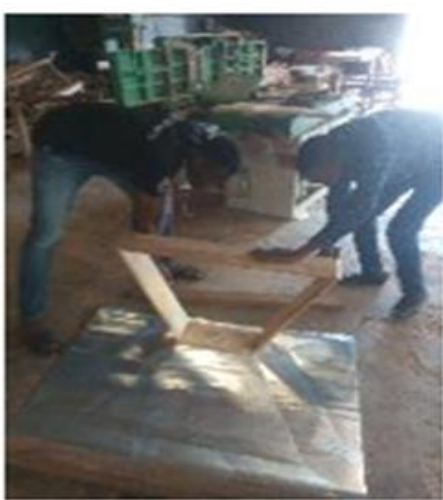

Plate 9: metal sheet for splash tray interior

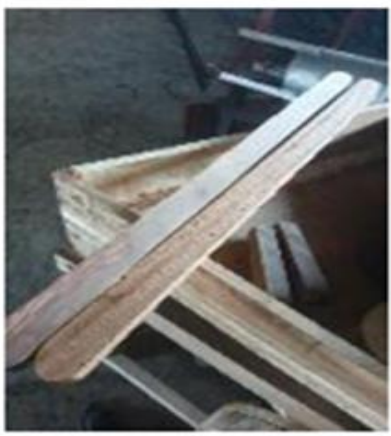

Plate 12: Kick Bars

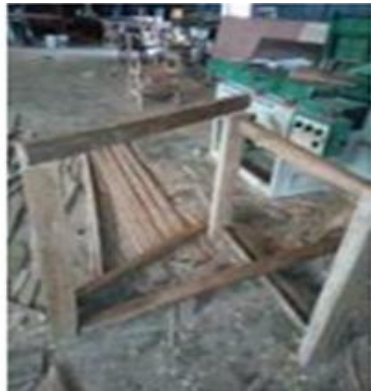

Plate 7: frame work

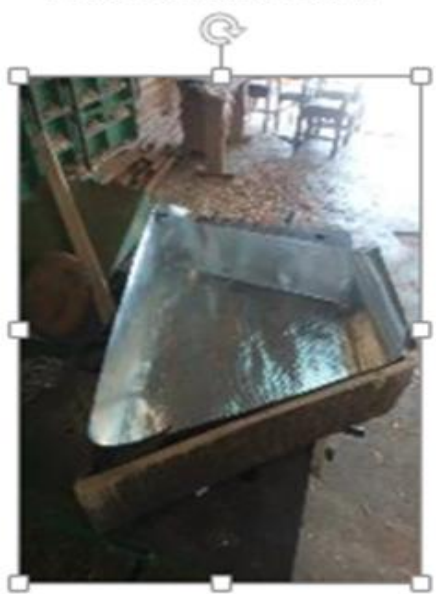

Plate 10: Splash tray lining

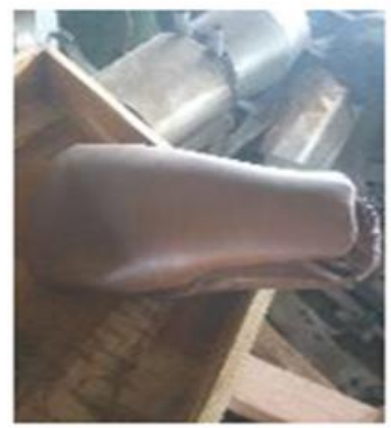

Plate 13: Wheel Seat

\subsection{Design Considerations}

The following was considered in the design of the various units/elements of the machine

- design maintenance

- the centralization of the entire system/balance and rigidity

- design for reliability and adequate duration of service

- design for safety

- ergonomics

- noise making/vibration

- the quality of whole materials used for the design

- design aesthetics

- economic worthwhile and operational consideration

- the wheel was also designed as a basis for product improvement for next generation design and design for different but related products 


\subsection{Design Description}

The Framework is a three footed assembly, rigidly screwed in places to support the weight of the motor axel, the lump of clay and the potter. The legs are constructed with a solid and robust 3x3inchesx3ft wood to attain the necessary rigidity and stability. However, any other solid metal rod (or hard wood) could be used [5]. This is braced together with 13 carriage bolts $6 \times 1 / 2$ inches to form a rigid structure for stability and durability. Holes are drilled into the joints to allow the screw hold the frame firmly together enough to withstand pressure from the user. A seating for the splash tray is also constructed on the topmost region of the framework with angle bars to support the splash tray when it is eventually mounted. A fairly thick flat wood measuring $25 \mathrm{~cm}$ by $25 \mathrm{~cm}$ is also screwed or nailed to the top of the third foot which will form the seat for the potter. The wood will eventually be covered with upholstery material to make it comfortable for the potter. A height of between $2 \mathrm{ft} 8$ inches is adequate for the machine $[4,5]$.

\subsection{Fabrication Process}

The fabrication process includes cutting, welding and carpentry

\subsubsection{Carpentry and Assembling}

This involves the cutting of wood to suitable sizes to fit the frame, cutting is based on tendon and mortis joints to enable the balance of the machine. The following are major tools used in fabricating the wheel

3.4.2. Circular saw: this is an electric powered saw that is installed and used to cut wood, whatever the size

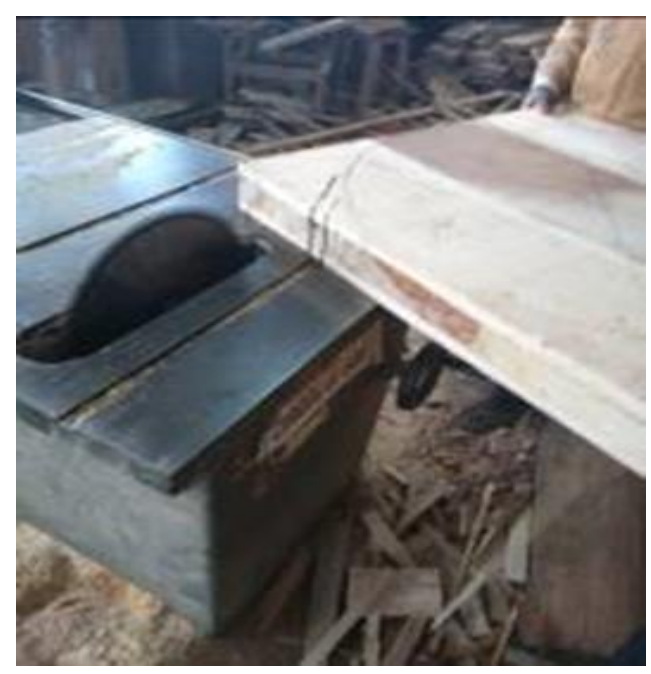

Plate 14 Circular Saw

\subsection{Welding}

This majorly focuses on the shaft, because it is the major metal part of the wheel, the shaft is welded to an 8inches iron bar that runs across the fly wheel, the angle bars that hold the splash tray to the frame is also metal, at an angle of $90^{\circ}$. Tools used for the metal parts:

- $\quad$ Pillar drilling machine with drilling bits $25 \mathrm{~mm}$ in size

- Hand drilling machine with $12 \mathrm{~mm}$ incise

- Welding machine

- Grinding machine

- 17, 13 spanner 


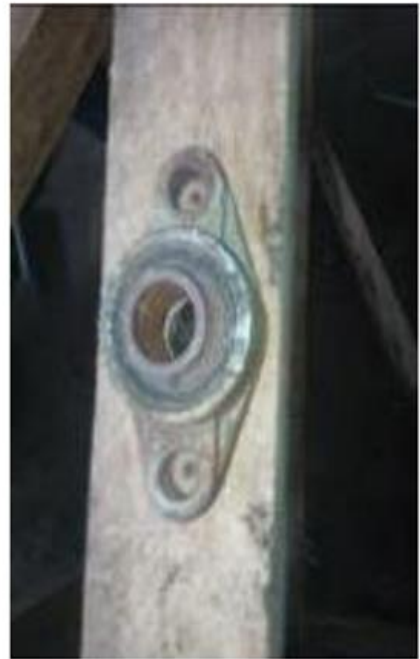

Plate 15: Fixing the Wheel Head Bearing

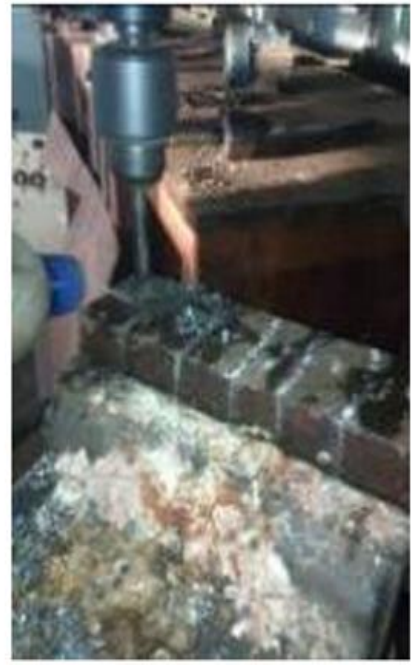

Plate 16: Cutting the splash tray Angle bars

\subsubsection{Spraying}

Materials used to spray the machinery are as follows:

- Thinner

- Sand filler

- Lacka

- Gloss

- Stain

- Sand paper

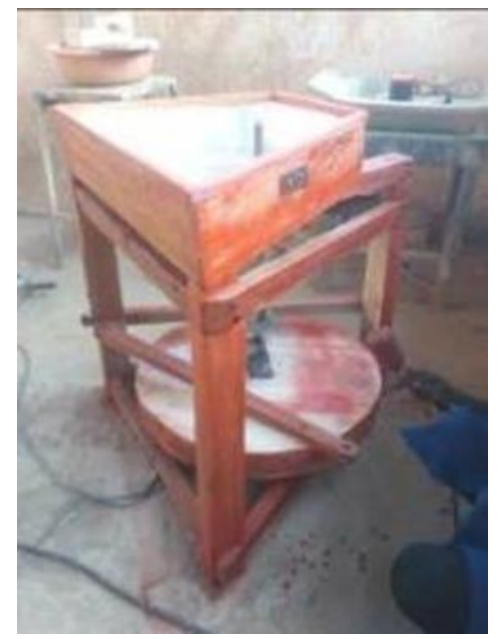

Plate 17 Spraying the Machinery 


\section{Results}
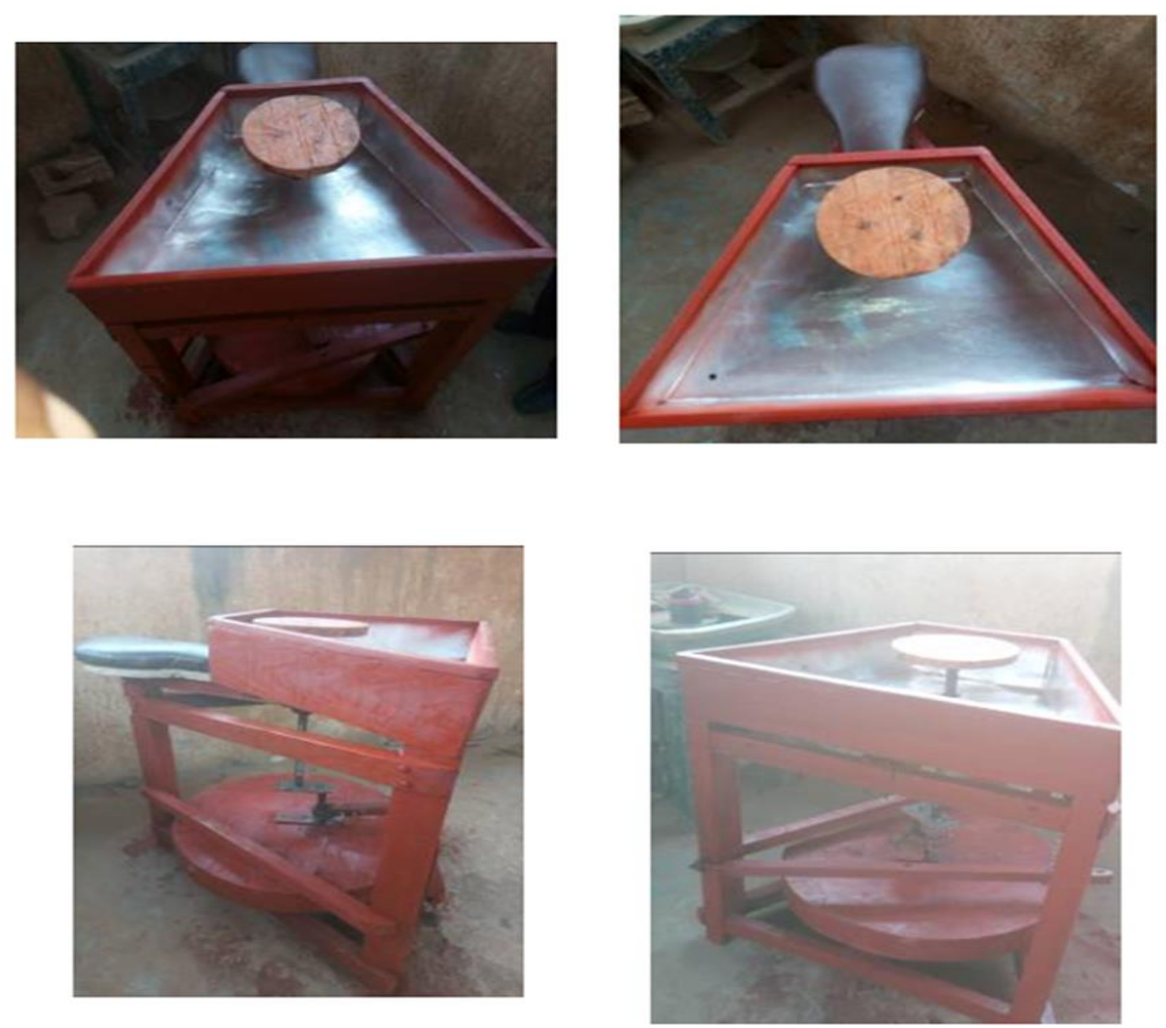

Plate 18 Finished Wheel

\section{Conclusion and recommendations}

This work has been made to meet up to some expectations such as being a reference point for future works that is in line with expected standards. It will also encourage giving preference to efficient manual equipment over the electric ones, and not to be bothered with failure in power supply which happens to be the major problems experienced in this part of the country. This potter's wheel will also be of good use in terms of ergonomics.

Finally, this work should be placed regularly on service so as to enhance workability and durability.

\section{Recommendations}

Considering the importance and great benefit of this project to local potters, it is recommended that

- Maintenance services being an important factor in the use of any equipment, so that equipment bought or fabricated will be well managed and used, thereby increasing its durability and its appreciation.

- Equipment should be serviced regularly in order to put off any form of fault ahead of time

\section{Compliance with ethical standards}

\section{Acknowledgments}

Acknowledgments must be inserted here. The authors acknowledge the effort of TET fund Nigeria and Centre for Research, Innovation and Development of the Federal Polytechnic Ado Ekiti, Nigeria for the research grant given to finance this work.

\section{aDisclosure of conflict of interest}

The authors declare no conflict of interest. 


\section{References}

[1] Leach B. A Potter Book. London, Faber And Faber Ltd., 1976

[2] Norton FN. Ceramics for The Artist Potter U.S.A Addision Wesley Publishing Company Inc. Technology, 1956.

[3] Naresh B. Potters Wheel Development. A Necessity for Rural Growth, Journal Of Rural, 2005.

[4] Hardy C. How To Build A Kick Wheel For Pottery. 2010.

[5] Agberia JT, Ladi Kwali Ibadan, Nigeria. Craft Books Ltd. 2007

[6] Agberia JT. Journal of Technology and Education In Nigeria Vol. 4 No 182.

[7] Etuokwu AD, Uzzi FD. Fabrication of Axel Kick Wheel for the Production Of Ceramics, International Journal Of Arts, Vol. 6. No. 2, 2016, 46 - 50.

[8] Bony A. Dsign (Edinburgh). Chambers Harrap Publishers Ltd. 2005.

[9] Primmer L. Pottery Made Simple. London. W. H Allen And Co. Ltd., 1976

[10] Cardew M. Pottery London Longman Group Limited, 1979. 